
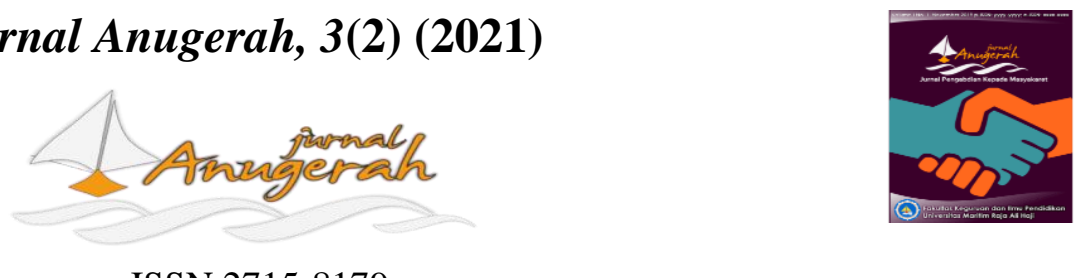

e-ISSN 2715-8179

https://ojs.umrah.ac.id/index.php/anugerah

\title{
Pelatihan Penerapan Pendekatan STEAM dalam Pembelajaran Biologi bagi MGMP Biologi Kota Tanjungpinang
}

\author{
Bony Irawan ${ }^{1}$, Elfa Oprasmani ${ }^{2}$, Adam Fernando ${ }^{3 *}$ \\ 1, 2, 3 Universitas Maritim Raja Ali Haji, Kota Tanjungpinang, Kepulauan Riau 29111, Indonesia \\ "e-mail korespondensi: adamfernando@umrah.ac.id
}

Pengiriman: 1 November 2021; Diterima: 17 November 2021; Publikasi: 30 November 2021

DOI: https://doi.org/10.31629/anugerah.v3i2.3881

\begin{abstract}
Abstrak
STEAM merupakan suatu pendekatan modern yang mampu menghasilkan pembelajaran yang menarik dan memberikan kerangka untuk penerapan konsep sains dalam memecahkan masalah sehari-hari dengan sistematika dan seni yang sesuai. Pendekatan STEAM dianjurkan untuk diterapkan di sekolah sebagai penyempurna dari pendekatan STEM yang sudah ada sebelumnya. Namun, dinamika dan perubahan pendekatan pembelajaran ini dirasakan sangat memberatkan bagi guru. Mitra pengabdian di MGMP Biologi Kota Tanjungpinang mengeluhkan cepatnya pergantian strategi pembelajaran yang dianut. Anggota MGMP belum tuntas berkenalan dengan pendekatan STEM, saat ini sudah muncul lagi pembaharuannya dalam bentuk pendekatan STEAM. Kesulitan yang dialami mitra ini membuat mereka tidak mampu untuk menerapkan pendekatan STEAM dalam pembelajaran biologi. Berdasarkan permintaan MGMP Biologi Kota Tanjungpinang, maka kami merumuskan kegiatan pengabdian kepada masyarakat ini untuk mengatasi permasalahan mitra tersebut. Bentuk pengabdian yang dilakukan berupa kegitan pelatihan dan pendampingan penerapan pendekatan STEAM bagi MGMP Biologi Kota Tanjungpinang. Kegiatan PKM ini dilakukan melalui rangkaian pelatihan tatap muka dengan guru-guru, dilanjutkan dengan penerapan dan uji coba pembelajaran dari hasil pelatihan yang sudah dilakukan. Pada bagian akhir dilakukan evaluasi untuk mengetahui keberhasilan program pengabdian dan respons peserta.
\end{abstract}

Kata kunci: STEAM; pembelajaran biologi; MGMP biologi; profesionalisme guru

\begin{abstract}
STEAM is a modern approach that can produce interesting learning and provide a framework for the application of scientific concepts in solving everyday problems with appropriate systematics and art. The STEAM approach is recommended to be applied in schools as a complement to the existing STEM approach. However, the dynamics and changes in this learning approach are felt to be very burdensome for teachers. Service partners at the Tanjungpinang City Biology MGMP complained about the rapid change in the learning strategies adopted. Subject Teacher's Forum (MGMP) members have not yet been fully acquainted with the STEM approach, now there has been another renewal in the form of the STEAM approach. The difficulties experienced by these partners made them unable to apply the STEAM approach in learning biology. Based on the request of the Tanjungpinang City Biology MGMP, we formulated this community service activity to overcome the partner's problems. The form of service carried out is in the form of training and mentoring activities for the application of the STEAM approach for the Tanjungpinang City Biology MGMP. This PKM activity is carried out through a series of face-to-face training with teachers, followed by the implementation and trial of learning from the results of the training that has been carried out. In the end, an evaluation is carried out to determine the success of the service program and the response of the participants.
\end{abstract}

Keywords: STEAM; biology learning; MGMP; teacher professionalism 


\section{Pendahuluan}

Ilmu pendidikan adalah bidang yang sangat dinamis dengan berbagai perubahan dan gagasan baru yang bertujuan untuk kemajuan sistem pendidikan. Dinamika yang begitu cepat dalam pergeseran tren praktik pendidikan ini terkadang menimbulkan masalah. Banyak guru di negara berkembang yang pada dasarnya kurang mendapatkan pembaruan dan pendampingan merasa kesulitan untuk mengukuti kemajuan ilmu pendidikan tersebut. Hal ini juga sedang terjadi di Indonesia. Oleh karena itu, diperlukan suatu pendekatan pembelajaran yang bermakna dan sederhana agar dapat mengatasi hal tersebut. Salah satu pendekatan pembelajaran terbaru yang dianggap unggul menurut Sari \& Rahma (2019) adalah pendekatan STEAM (science, technology, engineering, art, mathematics). Menurut Henriksen (2017), pendekatan STEAM telah menjadi suatu paradigma yang penting untuk menciptakan sebuah proses pembelajaran yang kreatif dan artistik. Pendekatan ini merupakan penyempuranaan dari pendekatan STEM yang telah lebih dulu diperkenalkan.

Menurut Zubaidah (2019), STEAM adalah suatu pendekatan pembelajaran yang dapat memberikan kesempatan kepada siswa untuk memperluas wawasannya terkait sains dan humaniora. Pada saat yang bersamaan, siswa juga dapat mengembangkan keterampilan yang diperlukan untuk berkembang pada masa saat ini. Keterampilan yang dimaksud adalah keterampilan kemampuan berpikir kritis, kemampuan kreatif, komunikasi, kerja sama, kepemimpinan dan keterampilan lainnya. Saat ini, pendekatan pembelajaran STEAM juga merupakan kunci utama di dalam dunia pendidikan untuk menghadapi era Society 5.0 yang kita rasakan saat ini. Pembelajaran STEAM dapat mengarahkan siswa untuk membiasakan diri untuk berpikir secara kritis, logis, kreatif, matematis, mampu bekerja secara saintifik dengan meningkatkan kemampuan berpikir tingkat tinggi terkait penggunaan big data (Yuliari et al., 2020). Pendekatakan ini menggabungkan aspek-aspek penting dalam kemajuan peradaban manusia dalam satu kerangka pembelajaran, yaitu:

1. Science (Sains)

Sains merupakan suatu proses berpikir secara sistematis berdasarkan hukum, teori, dan fakta yang ada untuk memberikan solusi terhadap permasalahan. Setiap masalah memiliki cara atau solusi penyelesaian yang tidak sama. Hal ini perlu diberikan suatu pendekatan khusus agar solusinya dapat digunakan secara komprehensif.

2. Technology (Teknologi)

Setiap orang memiliki cara tersendiri untuk belajar dan dapat berbeda satu sama lain, sehingga penggunaan teknologi dalam proses pembelajaran mampu memudahkan transfer illmu, seperti pengguanaan video pembelajaran. Dengan adanya teknologi, teknologi dapat membantu siswa untuk melewati proses pembelajaran terutama konsep-konsep yang abstrak. Konten-konten digital lainnya juga mudah diakses dan dibagikan kepada siapa pun sehingga proses pembelajaran menjadi lebih mudah dan bermakna.

3. Engineering (Teknik/rekayasa)

Poin ini menekankan pada berbagai Teknik/rekayasa yang digunakan untuk mencari solusi permasalahan di dalam kehidupan. Proses rekayasa ini dapat memunculkan pola berpikir kreatif untuk menciptakan ide-ide atau solusi baru. Contoh yang lebih sederhana adalah bagaimana mengubah cara belajar dengan menghafal melalui pembelajaran berbasis proyek agar siswa lebih mudah memahami dan pengalamannya dapat dirasakan sendiri sesuai dengan bidang ilmu yang ingin diberikan.

4. Art (Seni)

Seni adalah ukuran dari keindahan (estetika). Contohnya dapat kita lihat pada ketersediaan media pembelajaran yang menarik pada berbagai sumber seperti video, buku, majalah, atau media lainnya. Hal ini perlu menjadi pertimbangan agar dapat meningkatkan daya tarik siswa terhadap ilmu atau 
materi yang ingin disampaikan. Hal ini berdampak pada motivasi dan semangat belajar siswa dapat tinggi dan selalu terjaga dengan baik.

5. Mathematic (Matematika)

Matematika merupakan suatu proses berpikir terkait logika dasar bagaimana segala yang ada di dunia ini dapat diukur dan dievaluasi. Tujuannya adalah untuk membantu memberikan solusi terhadap permasalahan yang dihadapi setiap orang. Matematika juga berfungsi sebagai bahasa logika universal. Artinya, matematika adalah bahasa logika yang dapat diterima oleh seluruh dunia untuk mengomunikasikan suatu ilmu kepada orang lain.

Menurut Henriksen (2017), kelima hal ini dapat membantu guru untuk mengembangkan desain berpikir untuk mengembangkan suatu proses pembelajaran berbasis STEAM.

Pendekatan STEAM adalah solusi kompleks untuk mengembangkan sebuah pembelajaran yang bermakna, menarik, menantang, solutif, dan mengasah lebih banyak kemampuan peserta didik. Seperti halnya yang dikemukakan oleh (Komala \& Rohmalina, 2021) bahwa terdapat peningkatan kompetensi guru melalui pelatihan penerapan pendekatan STEAM ini. Namun penerapannya tidak mudah karena menuntut adanya perubahan mindset dalam memandang dan mengembangkan pembelajaran.

Permasalahan yang dialami oleh mitra pengabdian kepada masyarakat di sini antara lain:

1. Kesulitan mengikuti perkembangan ilmu pendidikan yang begitu dinamis

2. Belum mengenal pendekatan STEAM yang diinstruksikan untuk diterapkan di sekolah

3. Belum mampu menerapkan pendekatan STEAM dalam pembelajaran biologi

4. Adaptasi STEAM dari sistem pendidikan luar negeri ke sistem mata pelajaraan di Indonesia yang butuh banyak penyesuaian

5. Belum ada pendampingan dari pemerintah melalui dinas terkait untuk pelatihan dan pendampingan penerapan STEAM.

Solusi dari permasalahan yang telah dijelaskan sebelumnya adalah dengan melakukan pelatihan dan pendampingan terhadap mitra dalam penerapan pendekatan STEAM dalam pembelajaran biologi. Bentuk pelatihan ini dapat meningkatkan kompetensi guru dalam pengembangan pembelajaran, sekaligus menghasilkan produk perangkat pembelajaran yang dapat dipakai. Tim pengusul telah menyiapkan sebuah skema pelatihan penerapan STEAM dengan materi yang aplikatif bagi mitra.

Pelatihan penerapan pendekatan STEAM ini dibagi menjadi tiga fase, yaitu fase pemaparan materi, fase uji coba penerapan, dan fase evaluasi. Fase pemaparan bertujuan untuk membantu anggota MGMP mengembangkan desain instruksional pembelajaran biologi dengan menggunakan pendekatan STEAM. Pendampingan dilakukan dengan intensif untuk meningkatkan hasil yang ingin diperoleh. Hal ini terbukti penting berdasarkan pengalaman Anggoro, dkk. (2018) dalam kegiatan pelatihan peningkatan kemampuan pedagogik guru bahwa kegiatan pendampingan harus intensif agar para peserta berkomitmen terhadap arahan kerja yang diberikan. Fase evaluasi dilakukan dengan memberikan kuesioner mengenai persepsi peserta terhadap pelaksanaan PKM.

\section{Metode}

Program kemitraan ini dilakukan dalam bentuk pendampingan terhadap MGMP Biologi Kota Tanjungpinang yang dilaksanakan pada bulan Juli-November 2020. Kegiatan dibagi kedalam tiga fase: (1) Fase pelatihan pengembangan pembelajaran biologi dengan pendekatan STEAM, (2) Fase uji coba penerapan desain instruksional yang dikembangkan (3) Fase refleksi dan evaluasi. Fase pertama dilakukan dalam bentuk sharing materi dalam pertemuan klasikal yang dilakukan setiap minggu di lokasi yang ditentukan. Fase kedua 
JURNAL ANUGERAH, November 2021; 3(2): 69-75

e-ISSN 2715-8179

dilakukan guru di sekolah masing-masing dan pengusul melakukan pendampingan dan berkunjung mengamati proses ujicoba di sekolah. Fase ketiga dilakukan di akhir program dengan tujuan refleksi dan evaluasi.

Pada kegiatan ini, mitra tidak hanya berperan sebagai subyek yang dilatih dan ditingkatkan kompetensinya. Sebagai guru yang telah lama mengabdi, mitra juga berperan sebagai penyedia informasi penting terkait pengembangan desain pembelajaran yang tailor-made untuk daerah kepulauan ini. Guru akan menjadi informan terkait keadaan dan daya dukung di lapangan. Data yang penting untuk diketahui sebelum menyusun desain instruksional yang khas ini adalah keadaan sarana dan prasarana di sekolah masing-masing, keadaan awal siswa dalam hal minat bakat dan motivasi belajar, keadaan lingkungan pendidikan dan keadaan geografis di sekitar sekolah. Dengan mempertimbangkan berbagai modalitas tersebut, maka dapat disusun sebuah desain pembelajaran yang optimal dengan praktikalitas yang tinggi. Evaluasi luaran kegiatan ini dilakukan pada dua objek yaitu kualitas dokumen perangkat pembelajaran yang dihasilkan, serta praktikalitas perangkat tersebut dalam proses pembelajaran yang dilaksanakan para mitra. Evaluasi akan dilakukan oleh tim pengusul.

Langkah-langkah pelaksanan program kemitraan lebih lengkap dijabarkan dalam Tabel 1 berikut ini.

Tabel 1

\section{Metode Pelaksanaan Pelatihan}

\begin{tabular}{|c|c|c|}
\hline Langkah Kerja & Penanggung Jawab & Luaran \\
\hline Penyampaian materi tentang STEAM & Bony Irawan, M.Pd. & $\begin{array}{c}\text { Kesadaran dan penguasaan peserta terhadap konsep } \\
\text { pembelajaran STEAM }\end{array}$ \\
\hline Penyampaian materi tentang & Bony Irawan, M.Pd. & Penguasaan peserta terhadap teknik pengembangan \\
\hline pengembangan desain instruksional & & desain instruksional \\
\hline Penyampaian materi tentang & Elfa Oprasmani, M.Pd. & Penguasaan peserta terhadap konsep pengembangan \\
\hline pengembangan media pembelajaran & & media \\
\hline Pemaparan tentang konten materi & Elfa Oprasmani, M.Pd. & Indikator pembelajaran STEAM biologi yang \\
\hline biologi yang potensial & Bony Irawan, S.Pd., M.Pd. & dirumuskan oleh peserta \\
\hline Pengembangan desain instruksional & Bony Irawan, M.Pd. & Silabus, RPP, bahan ajar, dan media pembelajaran \\
\hline \multirow[t]{4}{*}{ STEAM } & Elfa Oprasmani, M.Pd. & STEAM biologi yang disusun oleh peserta \\
\hline & Adam Fernando, M. Pd & \\
\hline & Rasidin & \\
\hline & Dian Fitri & \\
\hline Evaluasi terhadap progres dan & Bony Irawan, M.Pd. & Penilaian terhadap progres dan perangkat \\
\hline perangkat pembelajaran yang & Elfa Oprasmani, M.Pd. & pembelajaran yang dihasilkan \\
\hline dihasilkan peserta & Adam Fernando, M.Pd. & \\
\hline
\end{tabular}




\begin{tabular}{ccc}
\hline Langkah Kerja & Penanggung Jawab & Luaran \\
\hline pelatihan & Bony Irawan, M.Pd. & Tabulasi saran dan masukan peserta pendampingan \\
& Elfa Oprasmani, M.Pd. \\
& Adam Fernando, M.Pd. \\
& Evaluasi dokumen perangkat pembelajaran dan praktikalitas pembelajaran \\
\hline
\end{tabular}

\section{Hasil dan Pembahasan}

Kegiatan pengabdian dengan tema "Pelatihan Penerapan Pendekatan STEAM dalam Pembelajaran Biologi bagi MGMP Biologi Kota Tanjungpinang" dilaksanakan melalui beberapa penyesuaian terkait pandemi COVID-19. Pelaksanaan pengabdian berlangsung pada bulan Juli dan Agustus bertempat di aula SMAN 4 Tanjungpinang diganti dengan pertemuan secara daring melalui aplikasi Zoom. Perkembangan COVID-19 yang kemudian mereda, memungkinkan untuk dilakukannya pertemuan tatap muka, namun proses pelaksanaannya harus berlanjut hingga November 2020. Dengan perubahan tersebut, maka jadwal pertemuan dapat diperbanyak untuk memantapkan konsep STEAM para peserta. Adapun dokumentasi kegiatan ini dapat dilihat pada Gambar 1 berikut ini.
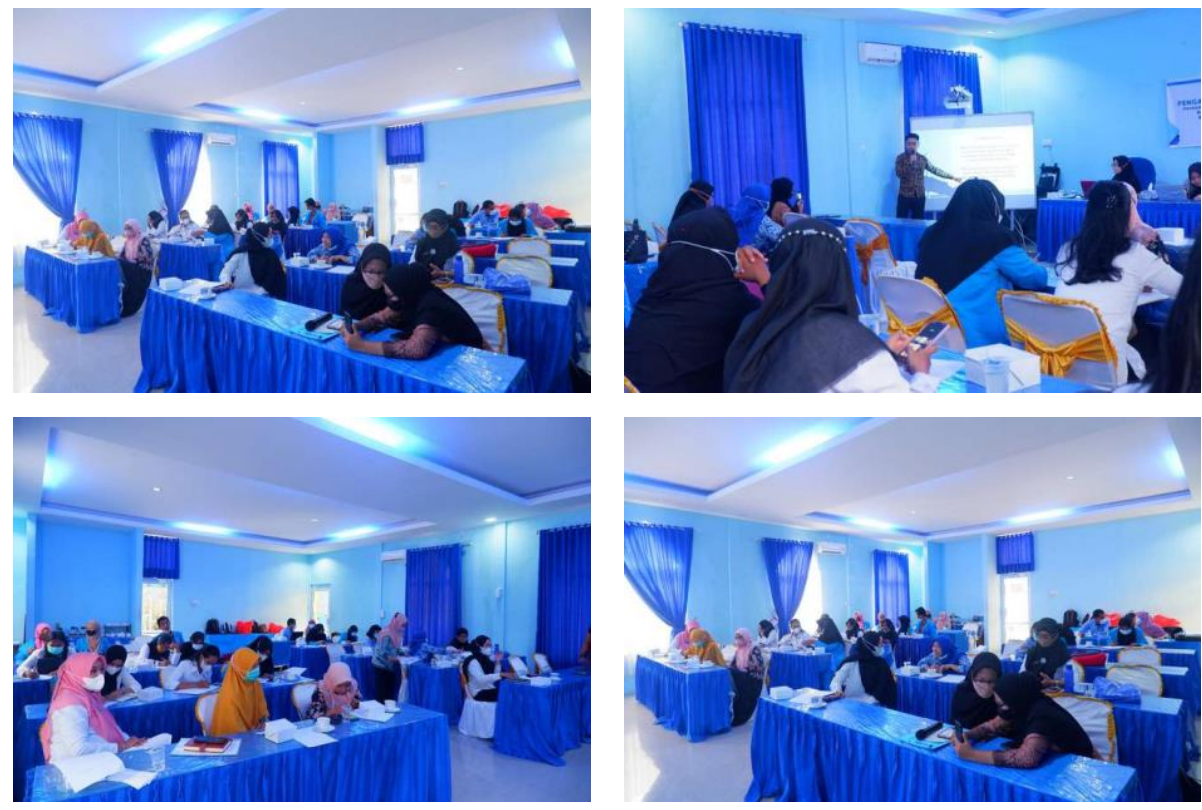

Gambar 1. Dokumentasi Kegiatan Pelaksanaan PKM

Melalui kegiatan ini para guru mendapatkan pemahaman dalam konsep pengembangan pembelajaran biologi dengan pendekatan STEAM. Jumlah peserta yang mengikuti kegiatan PKM ini sebanyak 23 peserta. Kegiatan ini dapat memberikan dampak positif untuk meningkatkan kualitas pembelajaran yang dilaksanakan di sekolah, terutama dalam kaitannya dengan pembelajaran biologi yang mengintegrasikan konsep STEAM. Hal tersebut dapat dilihat pada evaluasi kegiatan yang diberikan oleh peserta pada grafik berikut ini. 


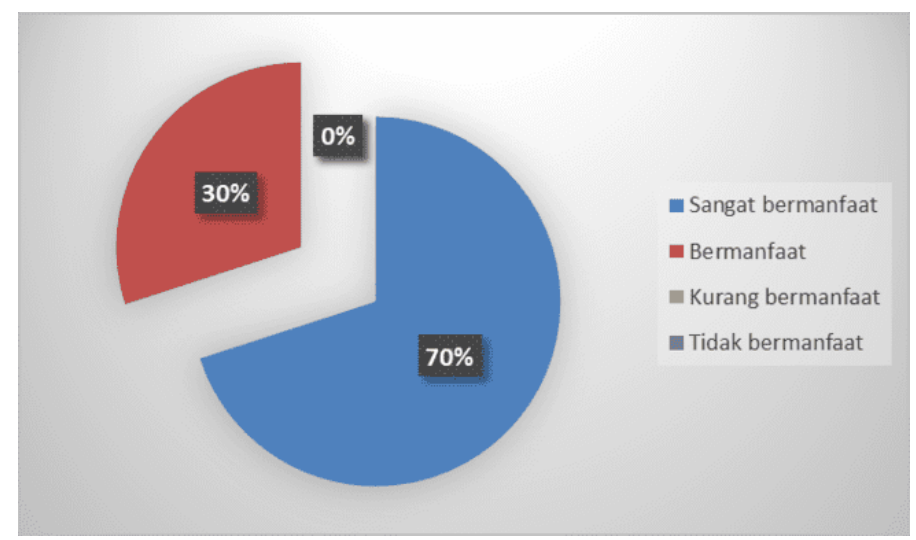

Gambar 2. Grafik Persepsi Peserta terhadap Pelaksanaan PKM

Berdasarkan Gambar 1 terlihat bahwa kegiatan pelatihan ini memiliki manfaat bagi guru-guru dalam menerapkan pendekatan STEAM ini. Hal ini juga ditemukan Sartono dkk. (2020) bahwa terdapat manfaat yang signifikan dirasakan oleh guru-guru yang mengikuti pelatihan penerapan pendekatan STEAM ini dengan baik, yang ditandai dengan tingginya tingkat partisipasi peserta pelatihan yang terlibat penuh dalam kegiatan ini. Guru-guru menjadi lebih antusias karena pendekatan STEAM ini dapat meningkatkan daya berpikir. Hal ini sesuai dengan pendapat Henriksen (2017) bahwa kebanyakan guru masih belum yakin dengan potensi dirinya sendiri, sehingga perlu memberikan beberapa kali pertemuan kegiatan ini agar guru-guru mampu memahami konsep pendekatan STEAM ini secara utuh. Dalam pengabdian ini juga diukur data penerapan pendekatan STEAM yang telah dilakukan anggota MGMP pada pembelajaran yang mereka bina sebelumnya. Berdasarkan kuesioner yang disebarkan kepada peserta diketahui bahwa belum ada peserta yang pernah menerapkan pendekatan STEAM sebelumnya (frekuensi 0\%). Hal ini disebabkan oleh faktor kurangnya sosialisasi pendekatan STEAM kepada para pendidik. Lebih jauh ditanyakan kepada peserta terkait kesediaan mereka untuk menerapkan pendekatan STEAM pada pembelajaran yang akan mereka lakukan pada masa mendatang, seluruh peserta menyatakan bersedia mencoba menerapkan pendekatan STEAM dalam pembelajaran biologi yang akan mereka lakukan pada masa mendatang (frekuensi 100\%).

\section{Kesimpulan}

Kesimpulan yang dapat diambil dari kegiatan ini adalah STEAM merupakan suatu pendekatan modern yang mampu menghasilkan pembelajaran yang menarik dan memberikan kerangka untuk penerapan konsep sains dalam memecahkan masalah sehari-hari dengan sistematika dan seni yang sesuai. Kegiatan ini dapat memberikan dampak positif untuk meningkatkan kualitas pembelajaran yang dilaksanakan di sekolah, terutama dalam kaitannya dengan pembelajaran biologi yang mengintegrasikan konsep STEAM.

\section{Saran}

Pada kemitraan berikutnya diharapkan dapat terlaksana kegiatan yang bermanfaat untuk kemajuan Pendidikan dan peningkatan proses pembalajaran biologi di kedua belah pihak. Dalam kemitraan ini diperlukan upaya evaluasi dan penyesuaian kembali rencana kemitraan berdasarkan hasil evaluasi tersebut. Evaluasi ini dilakukan untuk mengetahui dampak pelatihan yang dilakukan terhadap perbaikan kualitas pembelajaran yang dilaksanakan di sekolah. pada tahap evaluasi juga akan dijaring pandangan guru terhadap program pelatihan yang telah dilaksanakan. Pada masa yang akan datang, kerja sama yang telah terjalin antara 
pelaksana dengan MGMP Biologi Tanjungpinang akan terus ditingkatkan dalam bentuk kemitraan dan pengabdian lanjutan dalam tema pengembangan pendidikan STEAM.

\section{Ucapan Terima Kasih}

Terima kasih kami sampaikan kepada LP3M UMRAH yang telah memfasilitasi kegiatan PKM ini sehingga dapat berjalan dengan lancar. Kemudian, kepada seluruh pihak di SMAN 4 Tanjungpinang yang telah berpartisipasi dalam kegiatan PKM ini. Tidak lupa kepada mahasiswa-mahasiswa yang ikut terlibat dalam membantu kegiatan PKM ini dari awal sampai akhir kegiatan.

\section{Referensi}

Anggoro, S., Harmianto, S., \& Yuwono, P. D. (2018). Upaya meningkatkan kemampuan pedagogik guru melalui pelatihan pembelajaran tematik sains menggunakan inquiry learning process dan science activity based daily life. JPPM (Jurnal Pengabdian Dan Pemberdayaan Masyarakat), 2(1). https://doi.org/10.30595/jppm.v2i1.1844

Henriksen, D. Creating STEAM with design thinking: beyond STEM and arts integration. (2017). STEAM, 3(1). https://doi.org/10.5642/steam.20170301.11

Komala, K., \& Rohmalina, R. (2021). Kompetensi guru PAUD dalam PJJ melalui pelatihan pendekatan STEAM pada masa covid-19. Aulad: Journal on Early Childhood, 4(1). https://doi.org/10.31004/aulad.v4i1.96

Sari, D. Y., \& Rahma, A. (2019). Meningkatkan pemahaman orang tua dalam menstimulasi perkembangan anak dengan pendekatan steam melalui program home visit. Jurnal Tunas Siliwangi, 5(2).

Sartono, N., Suryanda, A., Ahmad, T. L. S., Zubaidah, Z., \& Yulisnaeni, Y. (2020). Implemetasi STEAM dalam pembelajaran biologi: upaya pemberdayaan guru biologi Madrasah Aliyah DKI Jakarta. BAKTIMAS: Jurnal Pengabdian Pada Masyarakat, 2(1). https://doi.org/10.32672/btm.v2i1.2099

Yuliari, N. K. R., Sumiyati, \& Hanim, W. (2020). Studi literatur pendekatan pembelajaran STEAM menyongsong era society 5.0. Prosiding Seminar Dan Diskusi ....

Zubaidah, S. (2019). STEAM (Science, Technology, Engineering, Arts, and Mathematics): Pembelajaran untuk memberdayakan keterampilan abad ke-21. Seminar Nasional Matematika Dan Sains, September. 